\title{
THE RISK OF HEARING LOSS ASSOCIATED WITH OCCUPATIONAL EXPOSURE TO ORGANIC SOLVENTS MIXTURE WITH AND WITHOUT CONCURRENT NOISE EXPOSURE: A SYSTEMATIC REVIEW AND META-ANALYSIS
}

\section{MARYAM HORMOZI ${ }^{1}$, ALIREZA ANSARI-MOGHADDAM ${ }^{2}$, RAMAZAN MIRZAEI', JAVID DEHGHAN HAGHIGHI ${ }^{3}$, and FATEMEH EFTEKHARIAN ${ }^{4}$}

${ }^{1}$ Zahedan University of Medical Sciences, Zahedan, Iran

Department of Occupational Health, Health Promotion Research Center

${ }^{2}$ Zahedan University of Medical Sciences, Zahedan, Iran

Department of Epidemiology and Biostatistics, Health Promotion Research Center

${ }^{3}$ Zahedan University of Medical Sciences, Zahedan, Iran

Community Medicine Department

${ }^{4}$ Shiraz University of Medical Sciences, Shiraz, Iran

Department of Health and Nutrition School Library

\begin{abstract}
This study is a meta-analysis of the previous epidemiological studies which investigated the quantitative estimates of the association between independent or combined exposure to noise and mixed organic solvents and hearing loss until October 2014. Overall, 15 studies with information on 7530 individuals ( $6 \%$ female) were included. Having assessed - by puretone audiometry - the adjusted odds ratio estimates for the association between solvents mixture exposure and the risk of developing hearing loss stood at 2.05 (95\% confidence interval (CI): 1.44-2.9). Similarly, for subjects who were concurrently exposed to noise and solvents mixture, an OR of 2.95 (95\% CI: 2.1-4.17) was obtained. There was some evidence of heterogeneity within each of the 2 exposure groups ( $p$ heterogeneity $<0.001)$. This heterogeneity was not explained by differences in strength of effect between duration of exposure, the number of solvent and exposure index in subgroups of solvents mixture exposure. Based on the available data, our analysis has provided the evidence of increased risk of developing hearing loss for workers exposed to organic solvents even at quite low concentration. Moreover, if such exposure is accompanied by noise, it will exacerbate the extent of hearing loss. Int J Occup Med Environ Health 2017;30(4):521-535
\end{abstract}

Key words:

Odds ratio, Occupational exposure, Organic solvents, Dose-response relationship, Hearing loss, Noise

Received: May 29, 2016. Accepted: November 9, 2016.

Corresponding author: R. Mirzaei, Zahedan University of Medical Sciences, Department of Occupational Health, Health Promotion Research Center, Seyed Razi 40, 9188733377, Zahedan, Iran (e-mail: rammir277@gmail.com). 


\section{INTRODUCTION}

Today work-related hearing loss is one of the main concerns of the occupational health and safety specialists. The U.S. National Institute for Occupational Safety and Health (NIOSH) has listed the work-related hearing loss as one of the priority research areas of the 21st century [1]. It is almost obvious that exposure to excessive levels of noise leads to hearing loss; usually known as noise-induced hearing loss (NIHL) [2-4]. Noise-induced hearing loss normally affects the inner ear and is characterized by the loss of auditory acuity, particularly in the range of $3-6 \mathrm{kHz}$ [5]. In an occupational context, the risk of hearing loss, increases with age, noise levels and duration of occupational noise exposure and will ultimately lead to permanent hearing loss. Such impairment is usually defined as a weighted average hearing loss at the audiometric test frequencies of 1, 2, 3, and $4 \mathrm{kHz}$ greater than $25 \mathrm{~dB}$ [6]. Strong evidence exists from several epidemiological studies that in addition to noise, exposure to mixed organic solvents for humans is associated with an excessive risk of developing hearing loss with and without concurrent noise exposure [7-34].

In industry, one of the most common kinds of exposure is reported to be exposure to solvents mixture. Over the past 3 decades, several studies investigated the relationship between occupational exposure to organic solvents mixture and hearing loss for humans. Workers from a wide range of industry sectors are usually exposed to mixtures of xylene, toluene, benzene, methyl ethyl ketone (MEK), methyl isobutyl ketene, ethanol, ethyl acetate, butyl acetate, ethyl benzene, cyclohexane, etc. The most prevalent exposures seem to happen in industries where workers have contacts with paints, thinners, lacquers and printing inks [35]. Although not well recognized in the case of humans, the ototoxic effects of organic solvents have been widely studied. There is no consensus about the correlation between the solvents exposure level and the resultant hearing loss. Hence the confirmation of a dose-response relationship between exposure to organic solvents and their ototoxic effects does not seem to be obtainable [23]. Previous experiments on animals and in particular on rats have confirmed the synergistic adverse effects of combined exposure to noise and solvents on hearing [36-40]. Though one of the drawbacks of such studies is that the subjects were usually exposed to high concentrations of solvents for short periods of time and is contrary to occupational exposure conditions. In the case of combined exposure to noise and organic solvents, depending on the parameters and characteristics associated to the noise (such as intensity and impulsiveness) and solvent (such as concentration), they might interactively affect each other. Previous investigations about the combined exposure also revealed that solvents had the capability of deteriorating noise-induced impairments even though the noise intensity level was below the permissible limits value $[3,22,41,42]$. It has also been cited that for noise and solvents, even if the single exposure is kept within current exposure limits, the co-exposure to them will synergistically increase the risk to hearing [43]. Several human studies, have also suggested that exposure to organic solvents at levels below current regulatory limits could still cause ototoxicity $[17,24,25,27,30,33,44,45]$.

Pure-tone audiometry (PTA) has been merely the common clinical test employed to determine the extent of hearing loss in occupational settings. It seems that the implementation of other clinical tests such as otoacoustic emission measurements would remarkably complement the data from pure-tone audiometry recordings [14]. Thus, it is necessary to devise an appropriate and comprehensive audiological test battery for solvent-exposed workers in occupational setting. Such a test should be precise enough to detect the hearing dysfunction as well as being suitable to be carried out for screening purposes [18]. To date, most of the studies about the concurrent exposure to noise and organic solvents have been considered to be cross-sectional and there has been a limited amount of human studies $[3,27,33]$ that longitudinally assess the risk of hearing loss in workers exposed to varied levels of organic 
solvents and noise. So far, no meta-analysis study has been published to investigate the relationship between occupational exposure to organic solvents mixtures and noise and the development of hearing loss, either alone or in combination with each other. Therefore, a meta-analysis study, which according to available data may provide us with reliable quantitative information on independent or combined exposures to noise and organic solvents on the one side and the risk of developing hearing loss on the other side, is warranted. One of the main objectives of this study is then to provide us with the insight into what we need to know about the hearing loss risk estimates of workers exposed to a mixture of solvents alone with special regard to the dose-response relationship.

\section{MATERIAL AND METHODS}

\section{Data sources}

Relevant studies were selected by a systematic search on PubMed, MEDLINE and a number of smaller databases using a MeSH heading search strategy and the key words such as hearing loss, noise, organic solvent mixture, combined exposure until October 2014. Titles and abstracts of the articles identified in our search results were reviewed. Then the abstracts which were clearly unrelated were excluded. Considering the criteria for inclusion of the studies, the full texts from all potentially eligible studies were determined and the relevant studies were eventually included. References from identified studies, as well as from the review and related articles, were also scanned to identify any other relevant studies. Two authors independently extracted the data using a specific form. We used no restrictions on publication year or publication status; however, languages were limited to English.

\section{Study selection}

\section{Hearing outcome evaluation}

We included studies that evaluated an increased risk for developing hearing loss (the probability of abnormal hearing threshold at any audiometric frequency) due to exposure estimates in odds ratio/relative risk calculations. We also included the studies in which noise and solventinduced hearing loss were considered as an outcome measure and hearing levels were assessed using the results of pure tone audiometry (air and bone conduction) as the evaluation method (Grason-Stadler GSI-61). An average hearing threshold greater than $25 \mathrm{~dB}$ in at least one ear was defined as the hearing loss (HL) $(250-8000 \mathrm{~Hz})$. Most of the studies, we included, had measured the levels of hearing loss with a calibrated audiometer and had followed a written protocol. Pure-tone audiometry is one of the major hearing tests which entails the participation of subjects to determine and measure the hearing sensitivity. For individuals who take part in this test the pure tone threshold is usually the lowest sound audible to them at least $50 \%$ of the time [18]. Due to the fact that workers in industrial settings might be exposed to complex exposure conditions, implementation of PTA may be really useful particularly when used as a screening tool to investigate the hearing disorders [21].

We only included the epidemiological studies which had investigated the risk of developing hearing loss in individuals occupationally exposed to a mixture of organic solvents alone or in combination with noise. The exposure to individual solvents was not covered by search.

\section{Exposure assessment to organic solvents mixture and noise}

An exposure index (EI) was used for expressing the level of exposure to organic solvents mixture. Regarding the fact that many industrial workers are usually exposed to multiple solvents we used EI for determining the influence of these solvents on the workers' total exposure load. In order to calculate the EI, the sum of the mean time-weighted exposures to each solvent was divided by its occupational exposure limit (American Conference of Governmental Industrial Hygienists threshold limit value - ACGIH TLV) and expressed as a unit value. Hence, EI $>1$ indicates that 
the organic solvent mixture concentration has exceeded the threshold limit [46].

Since in most of the previous studies the mean concentration of each solvent was below or slightly above occupational exposure limits, we employed 3 categories $(\mathrm{EI}<0.5$, EI $=0.5-1, \mathrm{EI}>1)$ to analyze the dose-response relationship between the level of exposure to the mixture of organic solvents and the risk of developing hearing loss. The current literature suggests that it takes about 2 to 3 years $[21,47]$ to 5 or more years of exposure for individuals to develop hearing loss from solvent exposures [22]. Thus, in order to take into account the relationship between the duration of exposure to the solvents mixture (the latency period) and the risk of developing hearing loss, we considered 3 follow-up times as important: the period shorter than 5 years, 5 to 10 years and more than 10 years.

We included all reported noise measurements according to a written national or international standard method. To make a distinction between the exposed and non-exposed subjects, only the admissible noise value (A-weighted sound pressure level of $85 \mathrm{~dB}$ ) was selected in a way that subjects who were exposed to $\geq 85 \mathrm{~dB}$ were considered as the noise exposed group. Since in the previous literature, the data about the noise intensity level in the combined exposure to noise and solvents mixture was quite scarce, we could not analyze the dose-response relationship in this group.

\section{Data extraction}

Two authors of this review (HM, AAM) independently extracted the data form studies that met inclusion criteria using a structured data-extraction form. The following information was abstracted: the first author, publication year, location of study, population characteristics, exposure assessment, risk estimates and variables controlled for in the analysis. Authors extracted the most relevant estimators including relative risk (RR) and odds ratio (OR) with their $95 \%$ confidence interval (CI). For epidemiological studies which did not report the risk of developing hearing loss in individuals, if the data was sufficient to determine a risk estimate (odds ratio/relative risk) and its $95 \% \mathrm{CI}$, it was calculated by the author using SPSS.

\section{Data synthesis}

For literature data, we made use of the random effects analysis to obtain pooled estimates of odds ratios (ORs) with $95 \%$ confidence intervals (95\% CI). Each study was weighted according to an estimate of its statistical size, which was defined as the inverse of the variance of $\log$ OR. Heterogeneity was tested with the $\mathrm{I}^{2}$ statistic and tested with the $\mathrm{Q}$ statistic. The heterogeneous data $\left(\mathrm{I}^{2}>50 \%\right)$, normally lead to the use of the random effects model as a more appropriate model [48]. Pooled ORs for the 2 exposure groups (solvents mixture alone, noise plus solvent mixture) were estimated and then compared with the reference group (workers without exposure to noise and solvents). Potential sources of heterogeneity were investigated by means of subgroups analyses. In addition, estimates were pooled separately to examine any dose-response relationship of solvents mixture exposed group that used 3 exposure index categories (e.g., $<0.5,0.5-1,>1$ ), duration of exposure and the number of solvent. The data analysis was performed using Stata, version 11.

\section{RESULTS}

Our search identified 13700 studies; out of which 175 were potentially relevant (Figure 1). A total of 15 epidemiological studies [20-34], from 2 cohort studies [27,33], and 13 cross-sectional studies, with information on a total of 7530 workers ( $6 \%$ female) were published to publicize estimates of the association between independent or combined exposure to noise and mixture of organic solvent and developing hearing loss were eligible for inclusion in 
Titles and abstracts of relevant papers identified through electronic search $(N=175)$

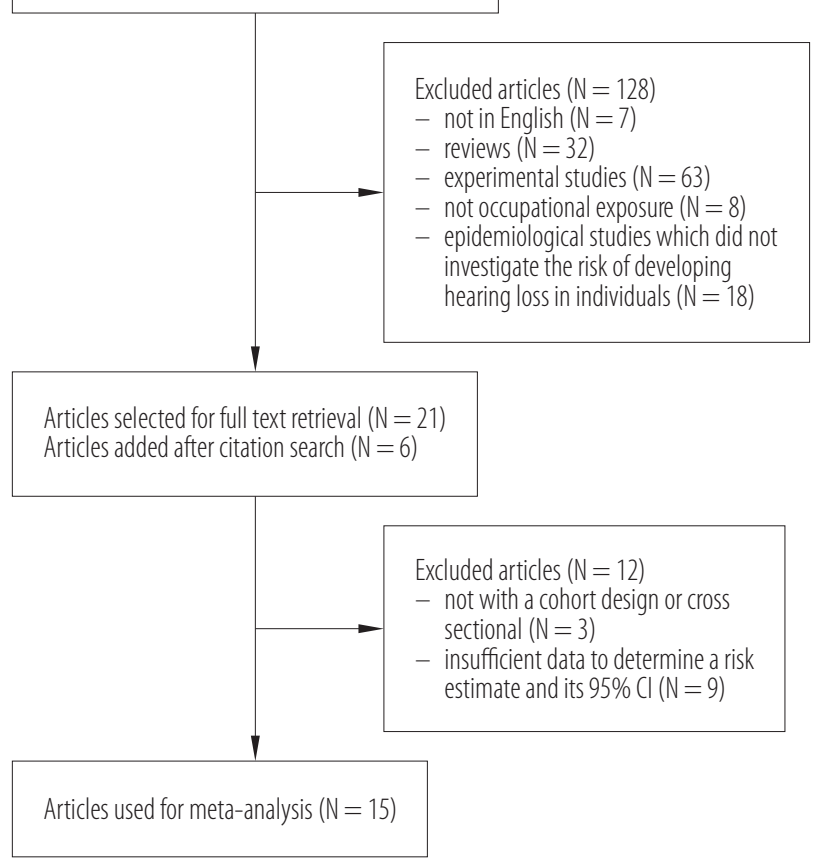

Fig. 1. Flow diagram of study selection for the meta-analysis of the association between exposure to noise and mixed organic solvents and risk of hearing loss

this meta-analysis. A summary associated with the characteristics of the included studies are shown in the Table 1.

The largest exposed groups were from paint and lacquer, dockyard, oil refinery, aviation, aluminum, air force reserve, automobile and petrochemical industries. The majority of the study populations were from; $\operatorname{Iran}(\mathrm{N}=2)$, Poland $(\mathrm{N}=4)$, USA $(\mathrm{N}=3)$, South America $(\mathrm{N}=2)$ with the remaining 3 studies from either Denmark or Egypt.

The included studies had employed the PTA test and medical records, or a combination of these 2 methods along with other diagnostic methods to record data related to hearing loss. In all included studies, the hearing loss was adjusted to a variable such as age. Researchers in some studies also included several other variables such as noise exposure, employment duration, gender, shooting or hunting, noisy hobbies, solvent exposure, alcohol consumption, hypertension, diabetes, smoking, noise trauma, and family history. These were particularly executed in the multivariate analysis of models.

Most literatures included in this study, assessing the auditory function in industrial workers concern the 3 categories of exposure:

- mixed solvents-only exposure,

- noise-only exposure,

- noise and mixed solvents exposure, when compared to non-exposed workers.

Our study design comprised 3 groups. The first one included 1135 workers who were exposed to organic solvents mixture alone (noise below $85 \mathrm{dBA}$ ), the second group consisted of 2493 workers exposed to organic solvents mixture and noise simultaneously and finally the reference group included 3902 individuals without exposure to noise and solvents. The main components of mixtures in organic solvents were xylene, toluene, methyl ethyl ketone (MEK), styrene, benzene, jet fuel. The pooled estimates odds ratio (OR) for cross-sectional and cohort studies for hearing loss in 2 exposed groups are shown in the Tables 2 and 3. The combined pooled estimate of association between solvents mixture exposure and risk of developing hearing loss from cross-sectional $(\mathrm{N}=10)$ and cohort studies $(\mathrm{N}=2)$ was 2.05 (95\% CI: 1.44-2.9) (Table 2). Similarly, pooled estimates OR for hearing loss in coexposure to noise and mixture of organic solvents from cross-sectional $(\mathrm{N}=10)$ and cohort studies $(\mathrm{N}=1)$ was 2.95 (95\% CI: 2.1-4.17) (Table 3).

There was some evidence of heterogeneity within each of the 3 exposure groups ( $p$ heterogeneity $<0.001$ ). This heterogeneity was not explained by differences in strength of effect between duration of exposure to solvent mixture, the number of solvent $(\mathrm{N}>5)$ and exposure in$\operatorname{dex}(E I=0.5-1$ and $>1)$ in subgroups of solvents mixture exposure (Table 4$)$. 


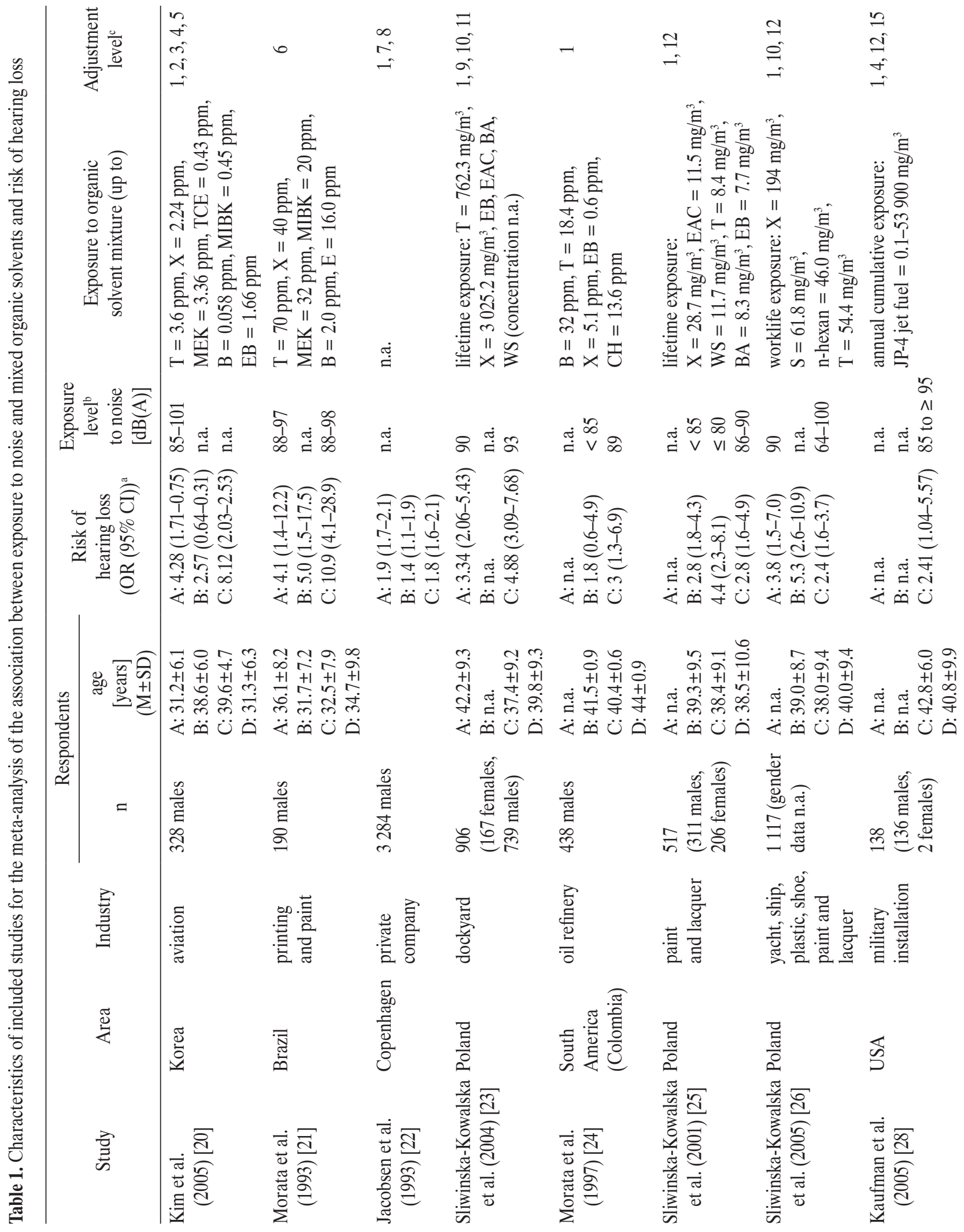




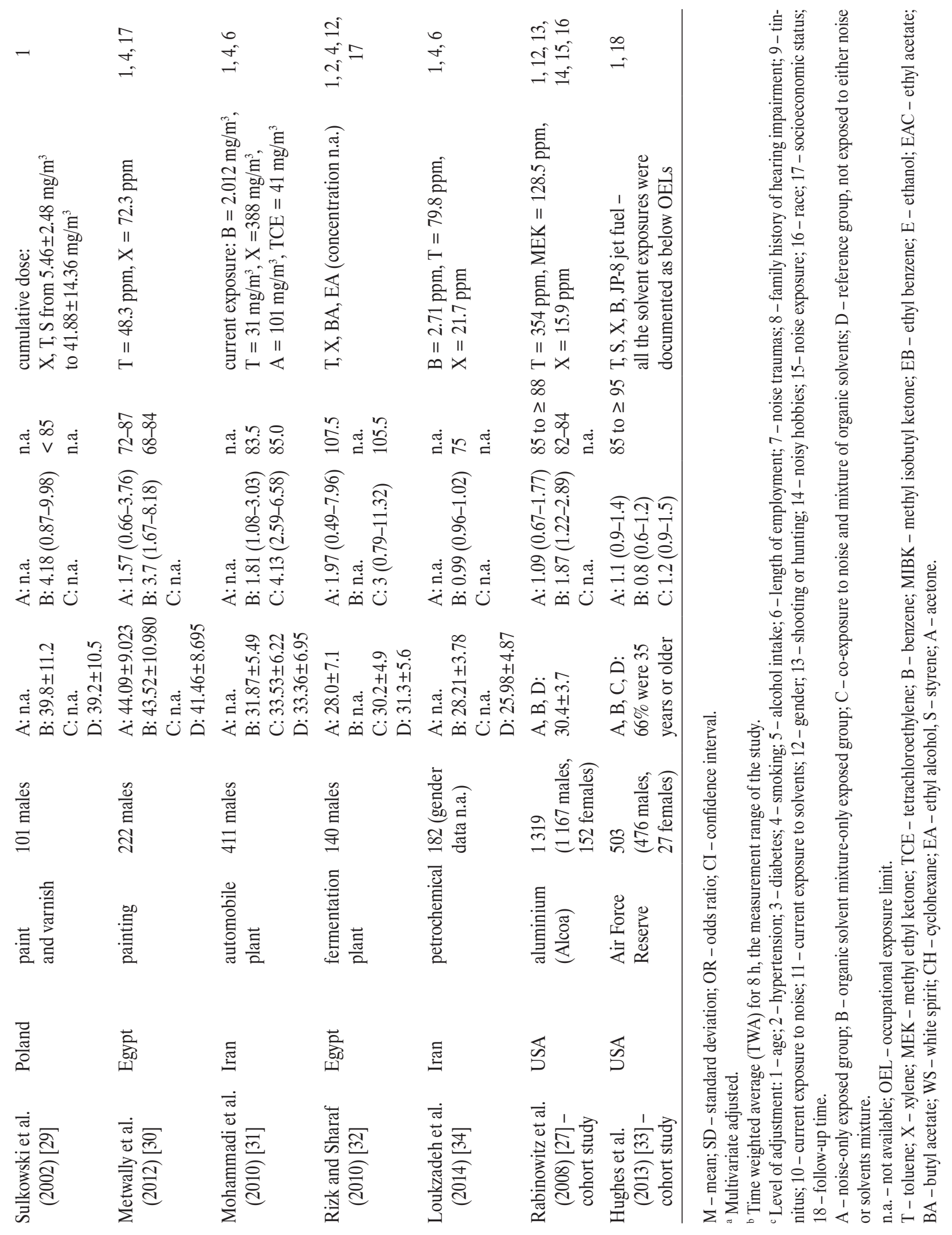


Table 2. Solvent mixture exposure and risk of hearing loss in a meta-analysis

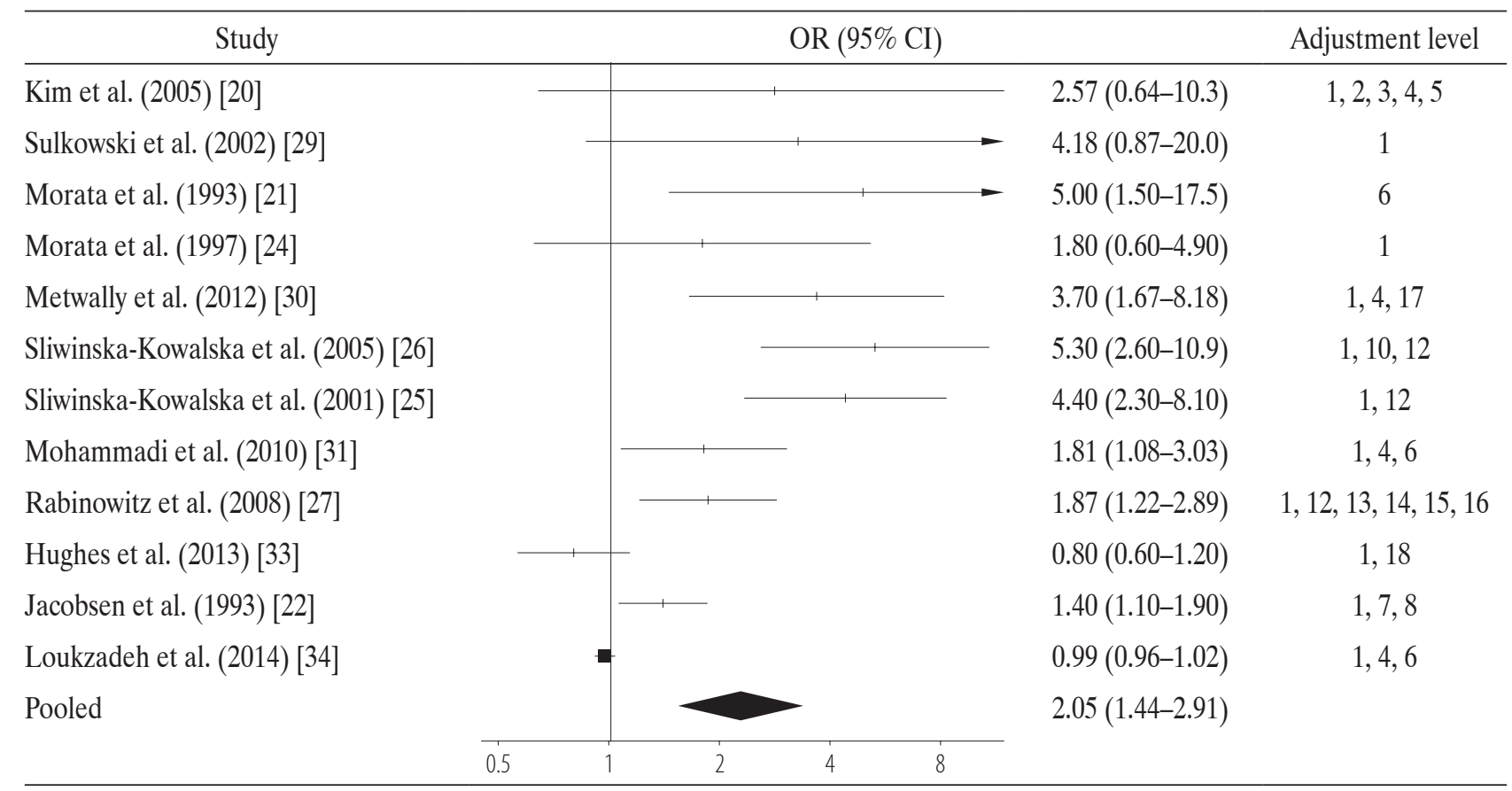

Abbreviations and adjustment levels as in Table 1.

$\%$ heterogeneity $(95 \% \mathrm{CI})=87 \%(79.5-92.0 \%)$, p for heterogeneity $<0.001$.

Table 3. Co-exposure to noise and solvents mixture and risk of hearing loss in a meta-analysis

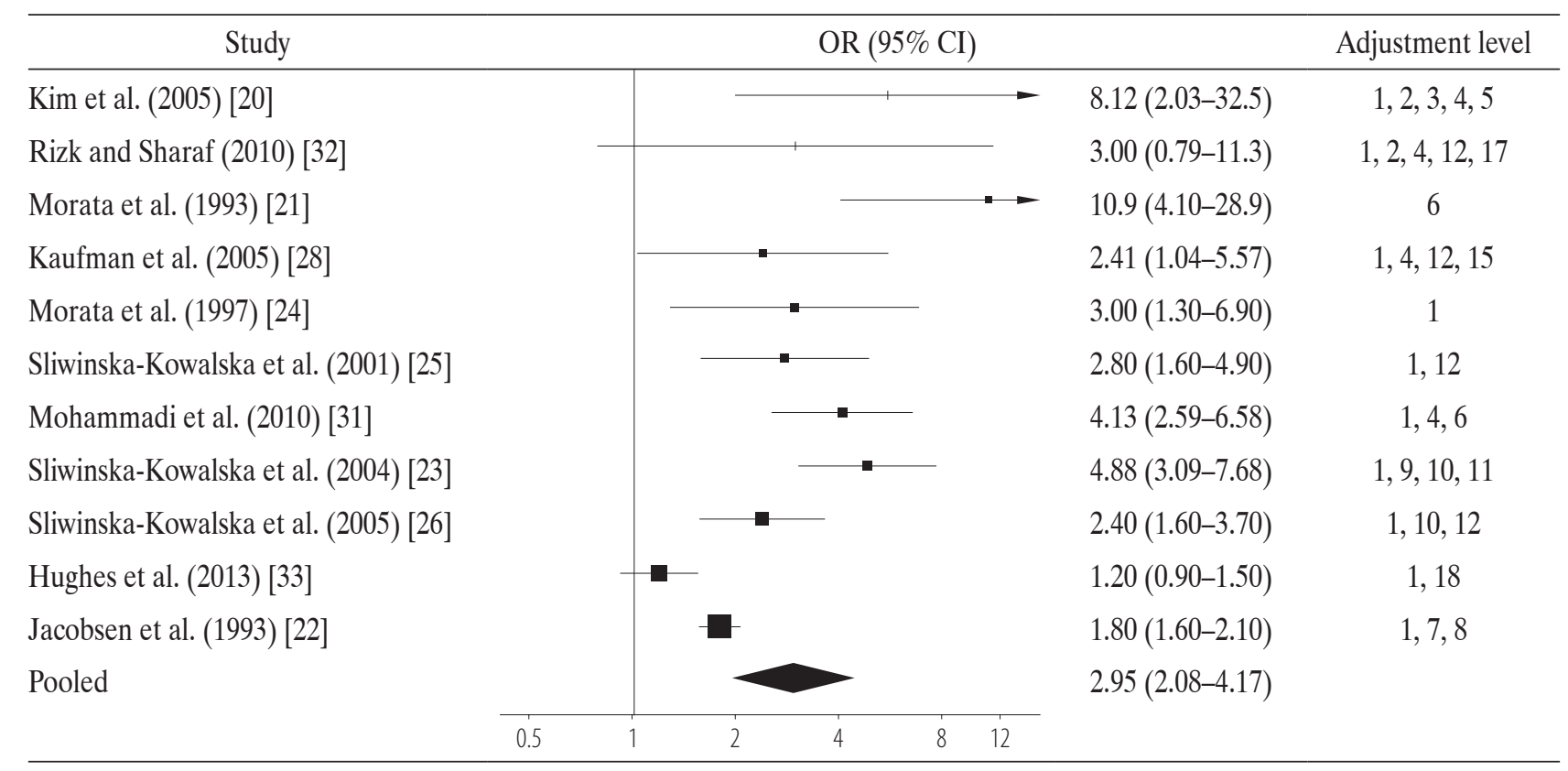

Abbreviations and adjustment levels as in Table 1.

$\%$ heterogeneity $(95 \% \mathrm{CI})=83.6 \%(72.0-90.3 \%)$, p for heterogeneity $<0.001$. 
Table 4. Dose-response relationship between organic solvents mixture exposure and risk of hearing loss*

\begin{tabular}{|c|c|c|c|}
\hline Variable & $\begin{array}{c}\text { Reports } \\
{[\mathrm{n}]}\end{array}$ & OR $(95 \% \mathrm{CI})$ & $\mathrm{p}$ \\
\hline Duration of exposure & & & 0.001 \\
\hline$<5$ years & 4 & $1.01(0.92-1.10)$ & \\
\hline $5-10$ years & 3 & $1.57(1.27-1.93)$ & \\
\hline$>10$ years & 7 & $3.36(2.36-4.79)$ & \\
\hline Exposure index (EI) & & & 0.049 \\
\hline$<0.5$ & 3 & $1.37(0.75-2.48)$ & \\
\hline $0.5-0.99$ & 3 & $3.25(1.88-5.62)$ & \\
\hline$\geq 1$ & 7 & $4.51(3.46-5.90)$ & \\
\hline Solvents & & & 0.045 \\
\hline $2-5$ & 7 & $1.62(1.07-2.44)$ & \\
\hline $6-8$ & 4 & $4.22(2.72-6.56)$ & \\
\hline
\end{tabular}

* Reference group was exposed neither to noise nor to solvents. Abbreviations as in Table 1.

\section{Dose-response relationship between exposure}

\section{to organic solvents mixture and risk of hearing loss}

In the presented meta-analysis in all 13 studies of the 15 selected studies had assessed the exposure to solvents mixture, in 8 studies, the concentration of individual solvents was below the occupational exposure limit. The assessment concerned current and/or cumulative concentration of every single solvent and current and/or cumulative exposure index. The results showed a statistically significant dose-response relationship between the level of solvent mixtures exposure and the risk of developing hearing loss. The adjusted odds ratio estimates for hearing loss for individuals with the highest exposure to organic solvents mixture $(\mathrm{EI} \geq 1)$, was 4.5 times greater (95\% CI: 3.46-5.9) and in those with moderate exposure $(\mathrm{EI}=0.5-1)-3.25$ times greater (95\% CI: 1.88-5.62) than the reference group who did not have exposure to noise and solvents mixture $(\mathrm{p}=0.049)$. The results also indicated that even individuals who were exposed to the lower concentrations of solvents mixture $(\mathrm{EI}<0.5)$, were prone to 1.37 higher risk of developing hearing loss $(\mathrm{OR}=1.37$, 95\% CI: 0.75-2.48) (Table 2).

Regarding the duration of exposure, there was a highly statistically significant difference between mixed solvent exposed groups $(\mathrm{p}<0.001)$. The pooled ORs estimates for the hearing loss among the individuals who had a record of 5 to 10 years of exposure to organic solvents increased up to 1.57 times; furthermore, this value, among the individuals who were exposed to such solvents for more than 10 years, increased to 3.36 times more than the reference group of those who were exposed to neither solvents nor noise $(\mathrm{OR}=1.57,95 \%$ CI: 1.27 1.93 vs. $\mathrm{OR}=3.36,95 \% \mathrm{CI}: 2.36-4.79)$. For individuals who had the lowest exposure history (less than 5 years) to solvent mixtures, no risk to hearing was observed (OR $=1.01,95 \%$ CI: 0.92-1.1).

Out of all 11 studies which reported the number of solvents present in the workplaces, workers in various industries were exposed to the minimum 2 and maximum 8 different organic solvents. The results from the pooled ORs in the 2 categories which considere 
the number of solvents suggests that the risk of developing hearing loss for individuals who were exposed to more than 5 solvents was 4.22 times (95\% CI: 2.72-6.56) and for those who had exposure to fewer than 5 solvents, was 1.62 times (95\% CI: 1.07-2.44) greater than the reference group of those who were exposed to neither solvents nor noise. Such evidence approves a positive correlation between the increase in the number of solvents (particularly if the number exceeds 6 ) and the risk of developing hearing loss $(\mathrm{p}=0.045)$.

\section{DISCUSSION}

The results of this meta-analysis of 7530 industrial workers indicated that the adjusted odd ratio estimates of hearing loss in each of 2 groups of exposure increased as compared to the reference group of those who were exposed neither to noise nor to solvents. The risk estimates of hearing loss were over 2 times greater for the solvents mixture group alone and about 3 times greater for individuals who were exposed to a combination of noise and organic solvent mixtures. These values indicate a higher effect of combined exposure to noise and solvents mixture on the risk of developing hearing loss. Previous epidemiological studies, indicate that an observed additive or even synergistic effect occurs from having combined exposures to noise and organic solvents mixture, by 2 to 11 times increase in the odds ratio of hearing loss [20-26,28,31].

It has been demonstrated that there is a synergistic causal effect caused by concurrent exposure to organic solvents mixture and noise in animal models [35]. However, in the case of human studies, the possible synergism of combined exposure to solvents and noise on hearing has not been consistently identified [7]. In industrial settings the individuals are usually exposed to the different levels and durations of noise and/or solvents and this makes it difficult to draw a conclusion that there is an interaction between solvents and noise on the risk of developing hearing loss in humans [16].
The results of our analyses have confirmed that simultaneous exposures to noise and organic solvents mixture produce a risk for developing hearing loss that is significantly greater than from either agent acting alone, as well as we suggest an increased risk of developing hearing loss in workers exposed to organic solvents mixture alone.

Most human studies have shown that solvents mixtureinduced hearing loss, with or without exposure to noise, is predominantly associated with an increased risk in higherfrequencies $(3,4,6$ and $8 \mathrm{kHz})[15,18,23-27,34]$ and it covers almost the entire region of frequencies tested, including the mid frequencies $(2-8 \mathrm{kHz})$ when assessed by PTA. This, however, may be dependent upon the type of solvent to which the worker is exposed [7].

Solvent-induced hearing impairment for humans not only involves the inner ear but also the central nervous system. Although there is strong research evidence that excessive generation of oxidative stress products are the underlying cause of developing hearing loss, animal studies also suggest that there are differences in mechanisms of solventinduced and noise-induced hearing loss in the cochlea in a way that solvents usually cause chemical poisoning, whereas noise causes mechanical damage [35]. Due to the fact that concentrations of organic solvents in occupational settings are usually much lower than the ones used in animal studies, it is more difficult to make a conclusion about their ototoxic effects of these solvents [48].

\section{Solvent mixture exposure level and risk of developing hearing loss}

A novel finding of this study is to show a dose-response relationship between exposure level (measured as exposure index) and duration for mixture of solvents and risk of occupational hearing loss. The analysis, however, found that when the exposure history was short $(<5$ years), the group who were exposed to organic solvents mixture did not show any excessive risk of developing hearing loss, compared to non-exposed population. Excessive risk 
was found for these workers with the increase in duration of exposure especially when exposure history was more than 10 years $(\mathrm{OR}=3.36)$. The increased risk of developing hearing loss associated with increasing solvents mixture level also existed in each category; particularly when the exposure level was moderate (exposure index between 0.5 to 1 ) and high (exposure index exceeding or equivalent one), ORs estimates were 3.25-fold and 4.5-fold, respectively. Moreover, when level of exposure to solvents was very low, ORs estimates were 1.37-fold for EI $<0.5$. This means that the concentration of individual solvents may be within exposure limits, but in combination they can still pose a risk. These results support a causal association between exposure to different levels organic solvents mixture and developing hearing loss.

There is evidence that exposures to very low concentrations of solvents (a few to tens of ppm for a given component of a mixture), probably do not produce any ototoxic effect [24]. However, it has been shown that moderate exposures to organic solvents mixture (below or around the occupational exposure limit (OEL) for each solvent), increase the odds ratio of developing hearing loss [25]. Those who are exposed to concentrations much above organic solvents OELs, there is a linear dose-response relationship between exposure level, the risk of hearing loss and hearing threshold at high frequencies (in principle $8 \mathrm{kHz}$ ), the odds ratio for hearing loss was 1.004 for each increment of the index of lifetime exposure to solvents [23].

In the cohort study, even though exposures level were low and the time of follow-up was quite short, workers developed additional hearing impairment at high frequencies which might be explained by peaks in solvent exposures and/or additional absorption of solvents through the skin. It seems that biological monitoring would be needed to assess such exposures [27].

The results from some studies show that short-term exposures with a mean work duration up to 4 years, to a mixture of solvents with or without exceeding permissible levels, might not affect the hearing threshold in puretone-audiometry [22,33,34]. Other occupational studies have demonstrated that the latency period for developing hearing loss from solvent exposures varies from 2 to 3 [21,47] or even 5 or more years of exposures [22]. Thus, it is possible that such period was not adequate to detect solvent-induced hearing loss among these study subjects and the period of latency before persistent loss appears to be dependent on the ototoxic and the characteristics of the exposure.

Kaufman et al. (2005) [28] showed that there was an increase in adjusted odds ratio for hearing loss; 1.7-fold among subjects who were exposed to noise and jet fuel for 3 years. They also found that for subjects who had a history of 12 years of exposure to both agents, the odds for hearing loss increased to 2.41. However, for those who had a combined exposure of more than 12 years the effects of jet fuel exposure on hearing were not statistically significant which might have been associated with a plateau effect for jet fuel exposure or the more dominant effect of noise-induced hearing loss as compared with the solventinduced hearing loss particularly for those who have prolonged history of exposure to both agents [28].

The results from the previous studies indicated that with the increasing number of solvents in a given mixture the risk of developing hearing loss increased [26]. Our analysis provided evidence that when the number of solvents exceeded 5, the risk estimate was 4.22 times higher. Several animal studies have confirmed that exposure to combinations of some solvents (mixtures of solvents) will contribute to greater hearing loss than it was found in single-solvent exposures [49-53]. The human studies have also confirmed such results [35].

The assessment of dose-response relationships are usually challenging and demanding. Such an assessment normally entails access to a large number of studies and detailed exposure information. Thus, the limitations of existing studies such as cross-sectional designs, insufficient 
characterization of the exposure levels and history for solvents and noise, and lack of calculation of working lifetime exposures in some studies must be taken into account. One of the limitations of pure-tone audiometry is that it is not capable of assessing hearing loss from combined exposure to noise and chemicals. This is usually due to the fact that it usually does not let the underlying source of the problem be diagnosed (i.e., cochlear vs. retro cochlear). In the case of central hearing loss, a PTA may lead to normal auditory test results. Thus, pure tone audiometry alone may underestimate the individual or combined effects of noise and organic solvents [14,54].

\section{CONCLUSIONS}

Based on the available epidemiologic data, our meta-analysis has provided the evidence increased the risk of developing hearing loss for workers exposed to organic solvents mixture with either increasing the level or duration of exposure. Moreover, simultaneous exposure to noise and organic solvents mixture produces a risk for developing hearing loss that is significantly greater than from either agent alone. The result from the studies must raise awareness among occupational physicians and decision makers that the current exposure limits for solvents (usually established separately for each single chemical) are not effective in protecting worker from developing hearing.

\section{REFERENCES}

1. Choi YH, Kim K. Noise-induced hearing loss in Korean workers: Co-exposure to organic solvents and heavy metals in nationwide industries. PLoS One. 2014;28:9(5):e97538.

2. Glaser RH. Preventing occupational hearing loss - A practical guide. Ear Hear. 1997;18(4):352-3, https://doi.org/10. 1097/00003446-199708000-00015.

3. Bergstrom B, Nystrom B. Developmen of hearing loss during long-term exposure to occupational noise a 20-year follow-up study. Scand Audiol. 1986;15:227-34, https://doi. org/10.3109/01050398609042148.
4. Daniell W, Swan S, McDaniel M, Camp J, Cohen M, Stebbins J. Noise exposure and hearing loss prevention programmes after 20 years of regulations in the US. Occup Environ Med. 2006;63:343-51, https://doi.org/10.1136/oem. 2005.024588 .

5. Rabinowitz PM, Galusha D, Slade MD, Dixon-Ernst C, Sircar KD, Dobie RA. Audiogram notches in noise-exposed workers. Ear Hear. 2006;27:742-50, https://doi.org/ 10.1097/01.aud.0000240544.79254.bc.

6. John AB, Kreisman BM, Pallett S. Validity of hearing impairment calculation methods for prediction of self-reported hearing handicap. Noise Health. 2012;14:13-20, https:// doi.org/10.4103/1463-1741.93321.

7. Fuente A, McPherson B. Organic solvents and hearing loss: The challenge for audiology. Int J Audiol. 2006;45:367-81, https://doi.org/10.1080/14992020600753205.

8. Gagnaire F, Langlais C. Relative ototoxicity of 21 aromatic solvents. Arch Toxicol. 2005;79:346-54, https://doi. org/10.1007/s00204-004-0636-2.

9. Henderson D. Solvents and hearing loss. J Am Acad Audiol. 1996;7:375.

10. Morioka I, Miyai N, Yamamoto H, Miyashita K. Evaluation of combined effect of organic solvents and noise by the upper limit of hearing. Ind Health. 2000;38:252-7, https://doi. org/10.2486/indhealth.38.252.

11. Skender L, Zabukosek J, Karaciæ V, Bilban M. Assessment of occupational exposure to organic solvents in paint industry. Arh Hig Rada Toksikol. 2000;51:287-94.

12. Morata TC, Dunn DE, Sieber WK. Occupational exposure to noise and ototoxic organic solvents. Arch Environ Health. 1994;49:359-65, https://doi.org/10.1080/00039896.1994. 9954988.

13. Morata TC, Little MB. Suggested guidelines for studying the combined effects of occupational exposure to noise and chemical on hearing. Noise Health. 2002;4:73-87.

14. Campo P, Morata TC, Hong O. Chemical exposure and hearing loss. Dis Mon. 2013;59:119-38, https://doi.org/10. 1016/j.disamonth.2013.01.003. 
15. De Barba MC, Jurkiewicz AL, Zeigelboim BS, de Oliveira LA, Belle AP. Audiometric findings in petrochemical workers exposed to noise and chemical agents. Noise Health. 2005;7:7-11, https://doi.org/10.4103/1463-1741.31873.

16. Prasher D, Al-Hajjaj H, Aylott S, Aksentijevic A. Effect of exposure to a mixture of solvents and noise on hearing and balance in aircraft maintenance workers. Noise Health. 2005;7:31-9, https://doi.org/10.4103/1463-1741.31876.

17. Unlu I, Kesici GG, Basturk A, Kos M, Yılmaz OH. A comparison of the effects of solvent and noise exposure on hearing, together and separately. Noise Health. 2014;16:410-5, https://doi.org/10.4103/1463-1741.144422.

18. Fuente A, Slade MD, Taylor T, Morata TC, Keith RW, Sparer J, et al. Peripheral and central auditory dysfunction induced by occupational exposure to organic solvents. J Occup Environ Med. 2009;51:1202-11, https://doi.org/10.1097/ JOM.0b013e3181bae17c.

19. Vyskocil A, Truchon G, Leroux T, Lemay F, Gendron M, Gagnon F, et al. A weight of evidence approach for the assessment of the ototoxic potential of industrial chemicals. Toxicol Ind Health. 2012;28:796-819, https://doi.org/ 10.1177/0748233711425067.

20. Kim J, Park H, Ha E, Jung T, Paik N, Yang S. Combined effects of noise and mixed solvents exposure on the hearing function among workers in the aviation industry. Ind Health. 2005;43:567-73, https://doi.org/10.2486/indhealth.43.567.

21. Morata TC, Dunn DE, Kretschmer LW, Lemasters GK, Keith RW. Effects of occupational exposure to organic solvents and noise on hearing. Scand J Work Environ Health. 1993;19:245-54, https://doi.org/10.5271/sjweh.1477.

22. Jacobsen P, Hein HO, Suadicani P, Parving A, Gyntelberg F. Mixed solvent exposure and hearing impairment: An epidemiological study of 3284 men. The Copenhagen male study. Occup Med. 1993;43:180-4, https://doi.org/10.1093/ occmed/43.4.180.

23. Sliwinska-Kowalska M, Zamyslowska-Szmytke E, Szymczak W, Kotylo P, Fiszer M, Wesolowski W, et al. Effects of co-exposure to noise and mixture of organic solvents on hearing in dockyard workers. J Occup Environ Med. 2004;46: 30-8, https://doi.org/10.1097/01.jom.0000105912.29242.5b.

24. Morata TC, Engel T, Durão A, Costa TR, Krieg EF, Dunn DE, et al. Hearing loss from combined exposures among petroleum refinery workers. Scand Audiol. 1997;26: 141-9, https://doi.org/10.3109/01050399709074987.

25. Sliwinska-Kowalska M, Zamyslowska-Szmytke E, Szymczak W, Kotylo P, Fiszer M, Dudarewicz A, et al. Hearing loss among workers exposed to moderate concentrations of solvents. Scand J Work Environ Health. 2001;27:335-42, https://doi.org/10.5271/sjweh.622.

26. Sliwinska-Kowalska M, Zamyslowska-Szmytke E, Szymczak W, Kotylo P, Fiszer M, Wesolowski W, et al. Exacerbation of noise-induced hearing loss by co-exposure to workplace chemicals. Environ Toxicol Pharmacol. 2005;19: 547-53, https://doi.org/10.1016/j.etap.2004.12.018.

27. Rabinowitz PM, Galusha D, Slade MD, Dixon-Ernst C, O'Neill A, Fiellin M, et al. Organic solvent exposure and hearing loss in a cohort of aluminium workers. Occup Environ Med. 2008;65:230-5, https://doi.org/10.1136/oem. 2006.031047.

28. Kaufman LR, LeMasters GK, Olsen DM, Succop P. Effects of concurrent noise and jet fuel exposure on hearing loss. J Occup Environ Med. 2005;47:212-18, https://doi. org/10.1097/01.jom.0000155710.28289.0e.

29. Sulkowski WJ, Kowalska S, Matyja W, Guzek W, Wesolowski W, Szymczak W, et al. Effects of occupational exposure to a mixture of solvents on the inner ear: A field study. Int J Occup Med Environ Health. 2002;15:247-56.

30. Metwally FM, Aziz HM, Mahdy-Abdallah H, ElGelil KS, El-Tahlawy EM. Effect of combined occupational exposure to noise and organic solvents on hearing. Toxicol Ind Health. 2012;28:901-7, https://doi.org/10.1177/074823371 1427051.

31. Mohammadi S, Labbafinejad Y, Attarchi M. Combined effects of ototoxic solvents and noise on hearing in automobile plant workers in Iran. Arh Hig Rada Toksikol. 2010;61: 267-74, https://doi.org/10.2478/10004-1254-61-2010-2013. 
32. Rizk SA, Sharaf NE. Health hazards among a sample of workers exposed to a combination of noise and organic solvents in a fermentation factory in Egypt. Nature Sci. 2010;8:95-9.

33. Hughes H, Hunting KL. Evaluation of the effects of exposure to organic solvents and hazardous noise among US Air Force Reserve personnel. Noise Health. 2013;15:379-87, https://doi.org/10.4103/1463-1741.121224.

34. Loukzadeh Z, Shojaoddiny-Ardekani A, Mehrparvar AH, Yazdi Z, Mollasadeghi A. Effect of exposure to a mixture of organic solvents on hearing thresholds in petrochemical industry workers. Iran J Otorhinolaryngol. 2014;26: $235-43$.

35. Śliwinska-Kowalska M, Prasher D, Rodrigues CA, Zamysłowska-Szmytke E, Campo P, Henderson D, et al. Ototoxicity of organic solvents - From scientific evidence to health policy. Int J Occup Med Environ Health. 2007;20:215-22, https://doi.org/10.2478/v10001-007-0021-5.

36. Johnson AC, Juntunen L, Nylén P, Borg E, Höglund G. Effect of interaction between noise and toluene on auditory function in the rat. Acta Otolaryngol. 1988;105:56-63, https://doi.org/10.3109/00016488809119446.

37. Lataye R, Campo P. Combined effects of a simultaneous exposure to noise and toluene on hearing function. Neurotoxicol Teratol. 1997;19:373-82, https://doi.org/10.1016/S08920362(97)00049-4.

38. Lataye R, Campo P, Loquet G, Morel G. Combined effects of noise and styrene on hearing: Comparison between active and sedentary rats. Noise Health. 2005;7:49-64, https://doi. org/10.4103/1463-1741.31633.

39. Mäkitie AA, Pirvola U, Pyykkö I, Sakakibara H, Riihimäki V, Ylikoski J. The ototoxic interaction of styrene and noise. Hear Res. 2003;179:9-20, https://doi.org/10.1016/ S0378-5955(03)00066-2.

40. Cappaert NL, Klis SF, Muijser H, Kulig BM, Smoorenburg GF. Simultaneous exposure to ethyl benzene and noise: Synergistic effects on outer hair cells. Hear Res. 2001;162: 67-79, https://doi.org/10.1016/S0378-5955(01)00373-2.
41. Chen GD, Henderson D. Cochlear injuries induced by the combined exposure to noise and styrene. Hear Res. 2009;254:25-33, https://doi.org/10.1016/j.heares.2009.04.005. 42. Vyskocil A, Leroux T, Truchon G, Lemay F, Gagnon F, Gendron $\mathrm{M}$, et al. Ototoxicity of trichloroethylene in concentrations relevant for the working environment. Hum Exp Toxicol. 2008;27:195-200, https://doi.org/10.1177/0960327108090267.

43. Prasher D, Morata T, Campo P, Fechter L, Johnson AC, Lund SP, et al. NoiseChem: An European Commission research project on the effects of exposure to noise and industrial chemicals on hearing and balance. Noise Health. 2002;4:41-8.

44. Morata TC, Johnson AC, Nylen P, Svensson EB, Cheng J, Krieg EF, et al. Audiometric findings in workers exposed to low levels of styrene and noise. J Occup Environ Med. 2002;44:806-14, https://doi.org/10.1097/00043764-20020900 $0-00002$

45. Morata TC, Sliwinska-Kowalska M, Johnson AC, Starck J, Pawlas K, Zamyslowska-Szmytke E, et al. A multicenter study on the audiometric findings of styrene-exposed workers. Int J Audiol. 2011;50:652-60, https://doi.org/10.3109/14 992027.2011.588965.

46. Rom WN. Occupational and environmental medicine. 4th ed. Philadelphia: Lippincott Williams \& Wilkins; 2007.

47. Morata TC. Study of the effects of simultaneous exposure to noise and carbon disulfide on workers' hearing. Scand Audiol. 1989;18:53-8, https://doi.org/10.3109/01050398909070723.

48. Woodward M. Epidemiology: Study design and data analysis. 2nd ed. Boca Raton (FL): Chapman \& Hall/CRC; 2005.

49. Campo P, Lataye R, Cossec B, Placidi V. Toluene-induced hearing loss: A mid-frequency location of the cochlear lesions. Neurotoxicol Teratol. 1997;19:129-40, https:/doi. org/10.1016/S0892-0362(96)00214-0.

50. Rebert CS, Boyes WK, Pryor GT, Svensgaard DJ, Kassay KM, Gordon GR, et al. Combined effects of solvents on the rat's auditory system: Styrene and trichloroethylene. Int J Psychophysiol. 1993;14:49-59, https://doi.org/10.1016/ 0167-8760(93)90083-2. 
51. Rebert CS, Schwartz RW, Svendsgaard DJ, Pryor GT, Boyes WK. Combined effects of paired solvents on the rat's auditory system. Toxicology. 1995;105:345-54, https://doi. org/10.1016/0300-483X(95)03232-5.

52. Nylen P, Hagman M, Johnson AC. Function of the auditory and visual systems, and of peripheral nerve, in rats after longterm combined exposure to n-hexane and methylated benzene derivatives. I. Toluene. Pharmacol Toxicol. 1994;74:11623, https://doi.org/10.1111/j.1600-0773.1994.tb01085.x.
53. Nylén P, Hagman M. Function of the auditory and visual systems, and of peripheral nerve, in rats after long-term combined exposure to n-hexane and methylated benzene derivatives. II. Xylene. Pharmacol Toxicol. 1994;74:124-9, https:// doi.org/10.1111/j.1600-0773.1994.tb01086.x.

54. Sliwinska-Kowalska M. Organic solvent exposure and hearing loss. Occup Environ Med. 2008;65:222-3, https://doi. org/10.1136/oem.2007.035907.

This work is available in Open Access model and licensed under a Creative Commons Attribution-NonCommercial 3.0 Poland License - http://creativecommons.org/ licenses/by-nc/3.0/pl/deed.en. 